\title{
Review of the genus Vibronychiurus (Collembola: Onychiuridae), with a description of two new species
}

\author{
ROMUALD J. POMORSKI \\ Institute of Zoology, Wrocław University, Sienkiewicza 21, P1-50-335 Wrocław, Poland; e-mail: onychus@biol.uni.wroc.pl
}

Key words. Collembola, Onychiuridae, Vibronychiurus, Palearctic, new species, new combination, diagnosis, key

\begin{abstract}
A new diagnosis of Vibronychiurus Pomorski, 1998 is given. V. archivari (Christiansen, 1956) comb. n. and V. hermonicus (Gruia, Poliakov \& Broza, 2000) stat. \& comb. n. are redescribed on the basis of the types and new specimens. Two new species are described: V. aestimabilis sp. n. from Khakasiya (Russia) and V. caucasicus sp. n. from Caucasus (Russia). A key to the species Vibronychiurus is provided.
\end{abstract}

\section{INTRODUCTION}

Thanks to the kindness of S. Stebaeva and Y. Sveenkova I have received two unidentified species of Vibronychiurus Pomorski, 1998, collected in Russia: South Siberia (Republic of Khakasiya) and the Caucasus. For comparison, I examined the types and other material of four species included in this genus, listed in the Checklist of Collembola [(http://www.geocities.com/ fransjanssens/taxa/onycinae.htm), updated on 2005.01.27]. Examination of this material has convinced me that:

1. The Russian material represents two new species of Vibronychiurus.

2. Onychiurus obsiones Cassagnau, 1963 actually belongs to the genus Onychiurus Gervais, 1841 and should be removed from the list of Vibronychiurus, because it has a distal whorl on tibiotarsi with nine setae and furca reduced to a finely granulated area with $2+2$ setulae in one row posteriorly.

3. Vibronychiurus archivari (Christiansen, 1956) comb. n. and Vibronychiurus hermonicus (Gruia, Poliakov \& Broza, 2000) stat. \& comb. n. were described inaccurately and both need redescriptions.

4. The diagnosis of the genus should be expanded, as a consequence of the discovery of two new species, which are described here.

The present work contains in addition a determination key to all species of the genus.

The nomenclature of morphological details used in the descriptions was adopted after Pomorski (1998a) and Fjellberg (1999).

\section{GENUS VIBRONYCHIURUS POMORSKI, 1998}

Type species. Vibronychiurus vinolentus Pomorski, 1998: 8 (by original designation).

Diagnosis. Cylindrical onychiurids with slightly broadened region of abdominal segments III-IV, with or without anal spines. Granulation uniform and fine, with stronger granules around anterior cephalic pseudocelli and submedian pseudocelli on abdominal tergum $\mathrm{V}$. Furca reduced to finely granulated area (divided in four parts as in Figs 16 and 20) with 1+1 setulae posteriorly, in contact with border between abdominal sterna III and IV. Sense organ of antennomere III with four or five papillae and smooth, straight sensory clubs. Vesicles in postantennal organ granulated. Labial palp A type. Dorsal chaetotaxy differentiated into apically rounded macro- and mesosetae and apically pointed microsetae. Sensilla on body indistinct. 1+1 microsensilla on thoracic terga II-III always present. Seta $\mathrm{d}_{0}$ on head present. Distal whorl on tibiotarsi with eleven setae. When present, male ventral organ located at ventral tube.

Remarks. The genus Vibronychiurus was established by Pomorski (1998b), based on Vibronychiurus vinolentus Pomorski, 1998 from Bulgaria and Turkey. A repeated examination of the type species revealed an error in the original diagnosis of the genus. The figure of labium had been drawn based on the right labial palp of the holotype, with broken papilla $\mathrm{C}$. The left labial palp of the holotype and palpi of all the paratypes are of $\mathrm{A}$ type.

The genus Vibronychiurus belongs to the group of genera of Onychiurini with eleven setae in distal whorl of tibiotarsi. The genus shares two characters with Onychiuroides Bagnall, 1948 and Deharvengiurus Weiner, 1996: the same structure of labium and a similar structure of the remnant of furca. It differs from them in the presence of only two posterior cephalic pseudocelli. Onychiuroides and Deharvengiurus have at least three pseudocelli, always arranged in a triangle.

\section{SPECIES DESCRIPTIONS}

Vibronychiurus archivari (Christiansen, 1956) comb. $\mathbf{n}$. Onychiurus archivari Christiansen, 1956: 28.

Redescription. Colour white. Length without antennae: Unreproductive male $1.1 \mathrm{~mm}$, female $1.1 \mathrm{~mm}$. Body cylindrical, somewhat broadened in the region of III-IV abdominal segments, with weakly curved anal spines, inserted without papillae (Figs 1 and 6). Antennae as long as head. Furca reduced to small depression, in contact with border between abdominal sterna III and IV, with 


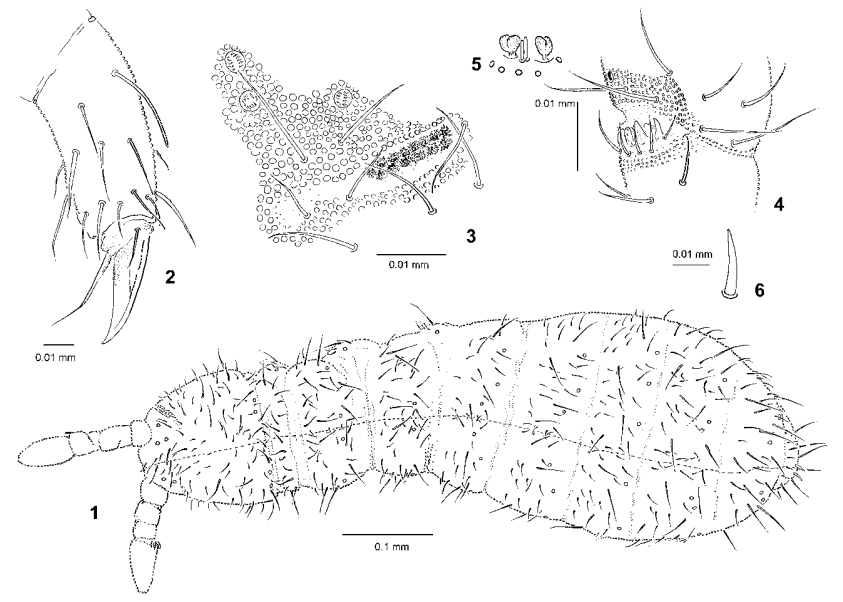

Figs 1-6. Vibronychiurus archivari (Christiansen, 1956) comb. n. 1 - habitus and dorsal chaetotaxy (paratype); 2 - tibiotarsal chaetotaxy and claw; 3 - postantennal organ and anterior cephalic pseudocelli; 4 - antennal III sense organ; 5 - sense organ of antennomere III, sensory clubs and rods; 6 - anal spine.

two small posterior setae. Granulation on dorsal body surface fine, regular, with coarsely granulated areas around anterior cephalic pseudocelli and submedian pseudocelli on abdominal tergum V. Antennal area not marked. Sense organ of antennomere III with four low conical papillae and five guard setae, two sensory rods and two sensory clubs, smooth, straight with one rib (Figs 4 and 5). Antennal segment IV with subapical organite and microsensillum located in row of posterior setae. Microsensillum on antennal segment III lateral and slightly posterior to antennal III sense organ. Postantennal organ consists of 14 very finely granulated vesicles (Fig. 3). Pseudocellar formula dorsally: 32/022/33333, ventrally no pseudocelli, formula of pseudocelli on subcoxa1: 1/1/1. Ventral parapseudocelli invisible (see Remarks), parapseudocelli on subcoxa1: 1/1/1. Labial palp of A type. Dorsal chaetotaxy symmetrical, well differentiated into macro- and mesosetae and apically pointed microsetae, as in Fig. 1. Sensory setae invisible. Abdominal tergum VI with one medial seta. Thorax II-III with lateral microsensilla. Subcoxae with 4, 5, 5 setae. Between legs on meso- and metasternum $1+1$ setae. Ventral tube with $6+6$ setae and two basal setae, without trace of male ventral organ (in unreproductive males). Claw without denticle, empodial appendage without basal lamella, distinctly longer than claw (Fig. 2).

Material examined. Three paratypes - two unreproductive males and female on three slides: 14 VI 1953, Lebanon, Barouk Cedars, 1,700 m alt., leg. K. Christiansen (housed in the Illinois Natural History Survey collection).

Remarks. The type material is strongly crumpled and for this reason the parapseudocelli are impossible to recognise.

The species is very closely related with $V$. vinolentus, from which it differs only in the absence of male ventral organ. Unreproductive males of $V$. archivari have no trace of differentiated setae on ventral tube.

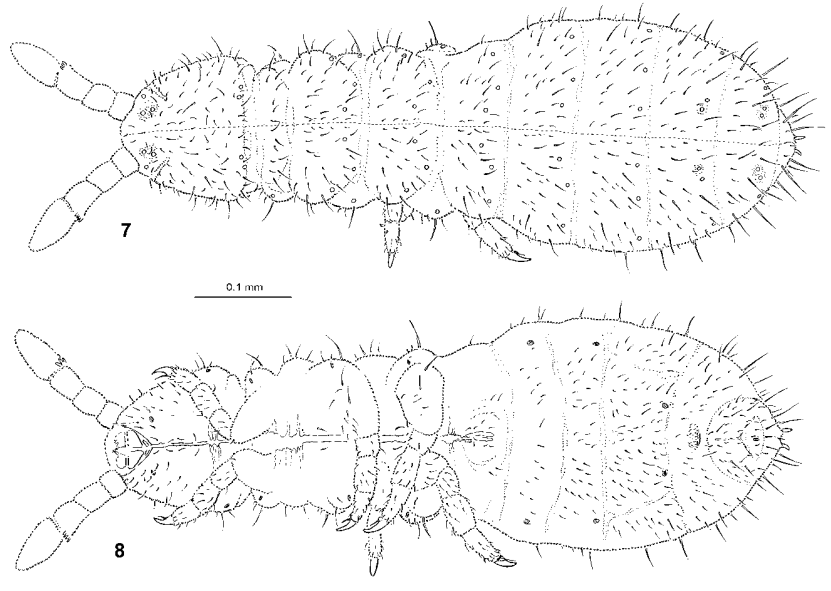

Figs 7-8. Vibronychiurus aestimabilis sp. n. (holotype). 7 habitus and dorsal chaetotaxy; 8 - habitus and ventral chaetotaxy.

\section{Vibronychiurus aestimabilis sp. $\mathbf{n}$.}

Diagnosis. $V$. aestimabilis sp. n. shares the presence of anal spines with $V$. archivari and $V$. vinolentus. The new species differs from both of them in its pseudocellar formula, the number of papillae in sense organ of antennomere III and a frequent presence of a denticle on the claw. $V$. aestimabilis has $3+3$ pseudocelli on thoracic terga II and III and five papillae in sense organ of antennomere III. The claws of $V$. archivari and $V$. vinolentus are always toothless, and they have $2+2$ pseudocelli on thoracic terga II and III and only four papillae in sense organ of antennomere III.

Description. Colour white. Length without antennae: Holotype $1.05 \mathrm{~mm}$, unreproductive males $1.0 \mathrm{~mm}$, females $1.0-1.1 \mathrm{~mm}$. Body cylindrical, distinctly broadened in the region of III-IV abdominal segments, with weakly curved anal spines, inserted without papillae (Figs 7 and 8). Antennae as long as head. Furca reduced to a small depression with finer granulation (divided in four parts), in contact with border between abdominal sterna III and IV, with two small posterior setae, as in Fig. 16. Granulation on dorsal body surface fine, regular, with somewhat coarser granules around anterior cephalic pseudocelli and submedian pseudocelli on abdominal tergum V. Antennal area not marked. Sense organ of antennomere III with five low conical papillae and five guard setae, two sensory rods and two sensory clubs, smooth, straight with one rib (Figs 12 and 13). Antennal segment IV with subapical organite and microsensillum located in row of posterior setae. Microsensillum on antennal segment III lateral and slightly posterior to antennal III sense organ. Postantennal organ consists of nine (8-11) very finely granulated vesicles (Fig. 9). Pseudocelli: Dorsal 32/033/33333; ventrally no pseudocelli; subcoxae $1 / 1 / 1$. Parapseudocelli: Ventral 2/000/?11101 ${ }^{\mathrm{m}}$; subcoxae 1/1/1. Position of parapseudocelli shown in Figs 8 and 15. Labial palp of A type (Fig. 11). Dorsal chaetotaxy symmetrical, well differentiated into macro- and mesosetae and apically pointed microsetae, as in Fig. 7. Sensory setae invisible. Abdominal tergum VI with 2(1) medial 


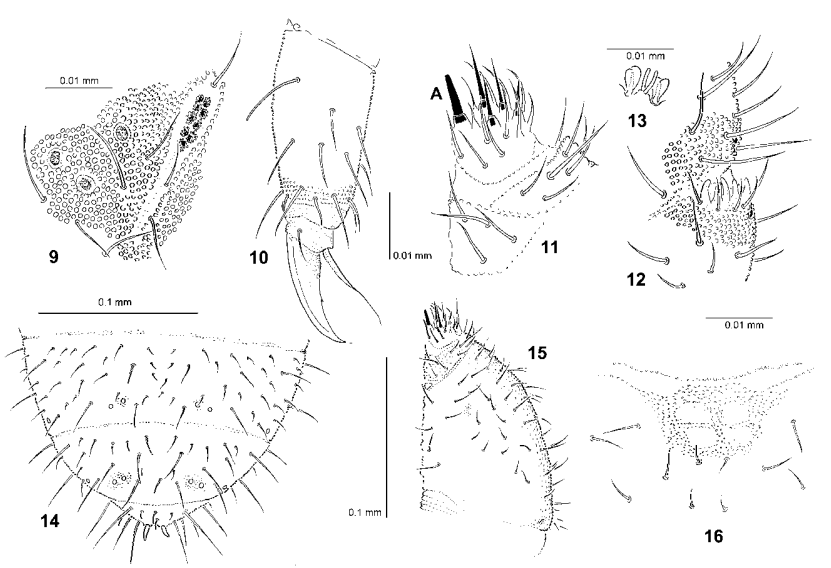

Figs 9-16. Vibronychiurus aestimabilis sp. n. 9 - postantennal organ and anterior cephalic pseudocelli; 10 - tibiotarsal chaetotaxy and claw; 11 - labial palp (A thickened labial papilla); 12 - antennal III sense organ; 13 - sense organ of antennomere III, sensory clubs and rods; 14 - chaetotaxy and arrangement of pseudocelli on abdominal terga IV-VI; 15 chaetotaxy and arrangement of parapseudocelli on ventral side of head; 16 - remnant of furca.

setae. Thorax II-III with lateral microsensilla. Subcoxae with 4, 5, 5 setae. Between legs on meso- and metasternum $1+1$ setae. Ventral tube with $7+7$ setae and two basal setae, without a trace of male ventral organ (in unreproductive males). Claw with small ventral denticle or toothless, empodial appendage without basal lamella, distinctly longer than claw (Fig. 10).

Material examined. Holotype female (marked by arrow), four paratypes (two unreproductive males, two females) on the same slide as holotype: 23 VII 1990, Russia, Republic of Khakasya, Eastern macroslope of Kuznetskii Ala-Tau Mt. Range, Kommunar Mt., 1,700 m alt., tundra with Dryas oxyodonta and Betula rotundifolia, in soil under moss, leg. S. Stebaeva; 18 paratypes, unreproductive males and females on one slide, 24 VII 1990, same locality as holotype, tundra with Salix glauca or Alnus fruticosa, leg. S. Stebaeva; twelve paratypes, unreproductive males and females on one slide, 25 VII 1990, same locality and habitat as holotype, leg. S. Stebaeva (all housed in the Department of Biodiversity and Evolutionary Taxonomy, Wrocław University).

Etymology. The species name is derived from the Latin word "aestimabilis" - respectable, venerable. The species is dedicated to the eminent collembologist Sofiya K. Stebaeva, who kindly gave me the material for investigation.

\section{Vibronychiurus caucasicus sp. $\mathbf{n}$.}

Diagnosis. $V$. caucasicus sp. n. shares the absence of anal spines with $V$. hermonicus, from which it differs in fine structural details of the postantennal organ and in the claw structure. Postantennal organ of $V$. caucasicus consists of 10-11 vesicles and their bases are oval and separated from each other, while the organ of $V$. hermonicus consists of 10-14 vesicles with almost circular bases, sometimes in contact with each other. Claws of $V$. caucasicus are always toothless, claws of $V$. hermonicus have a small ventral denticle.

Description. Colour white. Length without antennae: Unreproductive male $1.25 \mathrm{~mm}$, female $1.35 \mathrm{~mm}$. Body

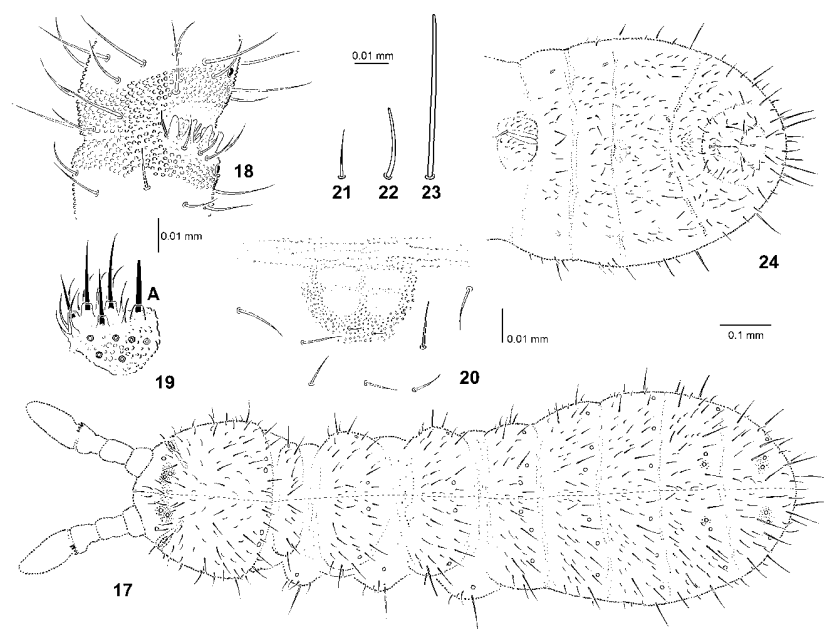

Figs 17-24. Vibronychiurus caucasicus sp. n. 17 - habitus and dorsal chaetotaxy (holotype); 18 - sense organ of antennomere III; 19 - labial palp (A thickened labial papilla); 20 - remnant of furca; 21 - microseta; 22 - mesoseta; 23 - macroseta; 24 - chaetotaxy and arrangement of parapseudocelli of abdominal sterna.

cylindrical, distinctly broadened in the region of III-IV abdominal segments, without anal spines (Fig. 17). Antennae as long as head. Furca reduced to small depression with finer granulation (divided in four parts), in contact with border between abdominal sterna III and IV, with two small posterior setae (Fig. 20). Cuticular granulation on dorsal surface of body fine, regular, with coarse granules around anterior cephalic pseudocelli and submedian pseudocelli on abdominal terga IV and V. Antennal area not marked. Sense organ of antennomere III with four papillae and five guard setae, two sensory rods and two sensory clubs, smooth, straight with one rib (Fig. 18). Antennal segment IV with subapical organite and microsensillum located in the row of posterior setae. Microsensillum on antennal segment III lateral and slightly posterior to sense organ antennomere III. Postantennal organ consists of 10-11 very finely granulated vesicles (Fig. 26), their bases oval and separated from each other (Fig. 27). Pseudocelli: Dorsal 32/022/33333; ventrally no pseudocelli; subcoxae 1/1/1. Parapseudocelli: Ventral 2/000/11101 ${ }^{\mathrm{m}}$; subcoxae 1/1/1. Labial palp of A type (Fig. 19). Dorsal chaetotaxy symmetrical, well differentiated into macro- and mesosetae (Figs 23, 22) and apically pointed microsetae (Fig. 21). Sensory setae invisible. Abdominal tergum VI with one medial seta. Thorax II-III with lateral microsensilla. Subcoxae with 4, 5, 5 setae. Between legs on meso- and metasternum 1+1 setae. Ventral tube with $7+7$ setae and two basal setae, without male ventral organ. Claw without denticle, empodial appendage without basal lamella, distinctly longer than claw (Fig. 25).

Material examined. Holotype unreproductive male (marked by arrow), three paratypes, (three females on the same slide as holotype): 6 VIII 2004, Russia, Kabardino-Balkaria, Tirnaus village, Caucasus Mts., canyon of Adyrsu river, "Skalnaya laboratoria" (Rocky Laboratory), little soil patches on big stones, in alpine meadows zone, 3,000 $\mathrm{m}$ alt., leg. Y. Sveenkova (all 


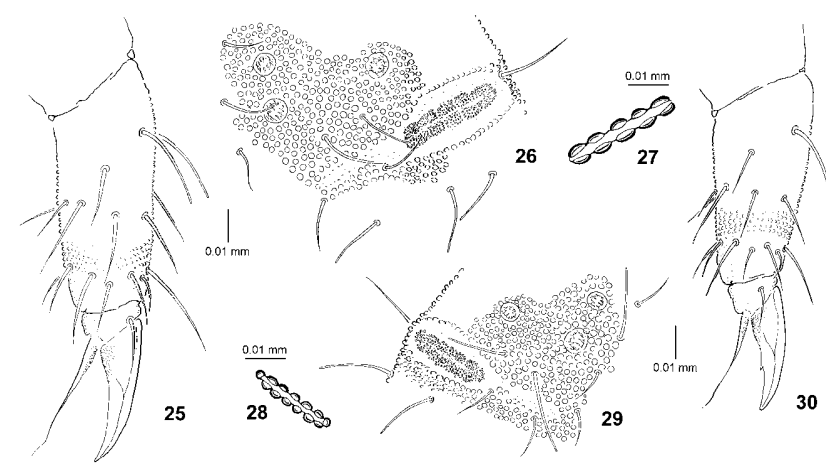

Figs 25-30. Vibronychiurus caucasicus sp. n. (25-27) and Vibronychiurus hermonicus (Gruia, Poliakov \& Broza, 2000) (28-30). 25 - tibiotarsal chaetotaxy and claw; 26 - postantennal organ and anterior cephalic pseudocelli; 27 - arrangement of basis of vesicles in postantennal organ; 28 - arrangement of basis of vesicles in postantennal organ; 29 - postantennal organ and anterior cephalic pseudocelli; 30 - tibiotarsal chaetotaxy and claw.

housed in the Department of Biodiversity and Evolutionary Taxonomy, Wrocław University).

Etymology. The species is named after its locality - the Caucasus Mts.

\section{Vibronychiurus hermonicus (Gruia, Poliakov \& Broza,} 2000) stat. \& comb. n.

Orthonychiurus gridelli hermonicus Gruia, Poliakov \& Broza, 2000

Redescription. Colour white. Length without antennae: Reproductive male $1.6 \mathrm{~mm}$, juvenile female $1.1 \mathrm{~mm}$. Body cylindrical, distinctly broadened in the region of III-IV abdominal segments, without anal spines. Antennae as long as head. Furca reduced to small depression with finer granulation (divided in four parts), in contact with border between abdominal sterna III and IV, with two small posterior setae. Cuticular granulation on dorsal surface of body fine, regular, with coarse granules around anterior cephalic pseudocelli and submedian pseudocelli on abdominal terga IV and V. Antennal area not marked. Sense organ of antennomere III with four papillae and five guard setae, two sensory rods and two sensory clubs, smooth, straight with one rib. Antennal segment IV with subapical organite and microsensillum located in row of posterior setae. Microsensillum on antennal segment III lateral and slightly posterior to sense organ of antennomere III. Postantennal organ consists of 11-14 very finely granulated vesicles (Fig. 29), their bases almost circular sometimes in contact with each other (Fig. 28). Pseudocelli: Dorsal 32/022/33333; ventrally no pseudocelli; subcoxae $1 / 1 / 1$. Parapseudocelli: Ventral 2/000/10101 ${ }^{\mathrm{m}}$; subcoxae 1/1/1. Labial palp of A type. Dorsal chaetotaxy symmetrical, well differentiated into macro- and mesosetae and apically pointed microsetae. Sensory setae invisible. Abdominal tergum VI with one medial seta. Thorax II-III with lateral microsensilla. Subcoxae with 4, 5, 5 setae. Between legs on meso- and metasternum $1+1$ setae. Ventral tube with $7+7$ setae and two basal setae, without male ventral organ. Claw with small ventral denticle, empodial appendage without basal lamella, distinctly longer than claw (Fig. 30).

Material examined. One adult male, two subadult male, two juveniles, 16 II 1999, Israel, Mount Carmel, Lower Nahal Oren, North slope, under Quercus caliprinos tree, litter + soil, leg. T. Pavlicek (housed in the Department of Biodiversity and Evolutionary Taxonomy, Wrocław University).

Remarks. So far I have been unable to examine the types of $V$. hermonicus, but five available specimens collected in the type locality (Mt. Carmel, Israel) fully agree with the original description with two exceptions (which I believe may be inaccuracies of that description). The species has parapseudocelli on the ventral side of the body and no lateral denticles on claws.

$V$. hermonicus was described as a subspecies of Onychiurus obsiones Cassagnau, 1963 and included in the genus Orthonychiurus Stach, 1954. Examination of the type material of $O$. obsiones shows that it belongs to the genus Onychiurus Gervais, 1841, and there is no close relationship between the two species. Two important characters of $V$. hermonicus (presence of eleven setae in the distal tibiotarsal whorl and labial palp of A type) show that the species undoubtedly belongs to the genus Vibronychiurus and therefore is hereby elevated to the species rank. Corresponding characters of Orthonychiurus are the following: nine setae in the distal tibiotarsal whorl and labial palp of $\mathrm{AB}$ type. $V$. hermonicus is closely related with $V$. caucasicus sp. n. described above (see diagnosis of $V$. caucasicus).

\section{KEY TO SPECIES OF VIBRONYCHIURUS}

1 Anal spines present. . . . . . . . . . . . . . . . . . . . 2

- Anal spines absent. ................... 4

2 Thoracic terga II and III with $2+2$ pseudocelli. . . . . . . . 3

- Thoracic terga II and III with $3+3$ pseudocelli (Russia; South Siberia, Khakasiya) ......... V. aestimabilis sp. n.

3 Ventral tube of adult males with ventral organ consisting of $1+1$ thick, robust setae, multifurcate at the end (Bulgaria, Turkey)................... V. vinolentus Pomorski, 1998 Males without ventral organ (Lebanon). .

.................. V. archivari (Christiansen, 1956)

4 Postantennal organ with 11-14 vesicles, their bases are almost circular sometimes in contact with each other (Fig. 28), claws usually with small ventral denticle (Israel). . . . . . ........ V. hermonicus (Gruia, Poliakov \& Broza, 2000) - Postantennal organ with 10-11 vesicles, their bases are oval and separated from each other (Fig. 27), claws without denticle (Russia: Caucasus)............ V. caucasicus sp. n.

ACKNOWLEDGEMENTS. I am most grateful to S. Stebaeva (Moscow) and Y. Sveenkova (State Nature Reserve "Privolzhskaya Lesostep", Penza) who kindly supplied me with the materials of both new species. I am indebted to K. Christiansen (Grinnel College, Grinnel), L. Deharveng (Museum of Natural History, Paris) and I. Kaprus' (Museum of Natural History, Lviv) for the loan of the types and other material of Vibronychiurus. Finally, I thank P. Svacha (the Editor of EJE) for valuable comments to the manuscript. The work is supported by grant No. 2020/W/IZ/03 from the Wrocław University. 


\section{REFERENCES}

Christiansen K. 1956: The Collembola of Lebanon and Western Syria. Part I. General considerations and the family Onychiuridae. Psyche 63: 119-133.

Fjellberg A. 1999: The labial palp in Collembola. Zool. Anz. 237: 309-330.

Gruia M., Poliakov D. \& Broza M. 2000: Collembola of Northern Israel, II. Contr. Biol. Lab. Kyoto Univ. 29: $117-131$.
Pomorski R.J. 1998a: Onychiurinae of Poland (Collembola: Onychiuridae). Genus 9 (Suppl.): 201 pp.

PoMORSKi R.J. 1998b: New Onychiurinae from Bulgaria and Turkey (Collembola: Onychiuridae). Pol. Pis. Entomol. 64: $3-11$.

Received October 11, 2005; revised and accepetd January 2, 2006 